\title{
RETRACTED ARTICLE: The Relation between Home Environment and Each Domain of Executive Function Skills of Children
}

\author{
Jin-Hyok Choe ${ }^{1}$ Jong-Hyok Choe ${ }^{1} \cdot$ Chung-Hyok Jang $^{1} \cdot$ Yun-Hui Sim ${ }^{2}$
}

Accepted: 8 April 2021 / Published online: 3 May 2021

(c) The Author(s), under exclusive licence to Springer Nature B.V. 2021

The Editor-in-Chief has retracted this article because it shows significant overlap with a previously published article by Korucu et al. [1]. Additionally, the authors have been unable to provide documents confirming that ethics approval was obtained for this study.

Jin-Hyok Choe stated on behalf of all co-authors that they agree to this retraction.

The online version of this article contains the full text of the retracted article as Supplementary Information.
Supplementary Information The online version contains supplementary material available at https://doi.org/10.1007/s10643-021-01189-y.

\section{References}

1. Korucu, I., Rolan, E., Napoli, A. R., Purpura, D. J., \& Schmitt, S. A. (2019). Development of the Home Executive Function Environment (HEFE) Scale: Assessing its relation to reschoolers' executive function. Early Childhood Research Quarterly, 47, 9-19. https://doi.org/10.1016/j.ecresq.2018.09.001
Jin-Hyok Choe

jh.choi0301@ryongnamsan.edu.kp

1 Kim Il Sung University, Pyongyang,

Democratic People's Republic of Korea

2 Pyongyang Teachers Training College, Pyongyang, Democratic People's Republic of Korea 